\title{
Corrosion of Single Layer Thin Film Protective Coatings on Steel Substrates for High Level Waste Containers
}

\author{
Michael A. Fusco ${ }^{1}$, Yasar Ay ${ }^{1}$, Abigail Casey ${ }^{2}$, Mohamed A. Bourham ${ }^{1}$, Leigh Winfrey ${ }^{2}$ \\ ${ }^{1}$ Department of Nuclear Engineering, North Carolina State University, Raleigh, NC 27695-7909, USA \\ ${ }^{2}$ Nuclear Engineering Program, University of Florida, Gainesville, FL 32611, USA
}

\begin{abstract}
Single-layer thin film coatings have been deposited on steel substrates and tested for their corrosion resistance. These coatings include $\mathrm{TiN}, \mathrm{ZrO}_{2}, \mathrm{TiO}_{2}, \mathrm{Al}_{2} \mathrm{O}_{3}$, and $\mathrm{MoS}_{2}$, and it is proposed that they will act as barriers to provide protection to the steel canisters that are part of the dry cask storage system for high level nuclear waste. Corrosion testing was completed using electrochemical potentiodynamic polarization techniques in aerated $1 \mathrm{M} \mathrm{NaCl}$ solution. Results show an exponential increase in corrosion rate with increasing temperature and an exponential decrease in the passive breakdown overpotential, which is directly related to the ability of a material to form and sustain a corrosioninhibiting passive film in a given environment. Additionally, kinetic activation parameters have been experimentally determined for each material, leading to predictive equations for corrosion rates. The bare and coated samples corrode analogously, indicative of pores allowing the coating and substrate to corrode simultaneously. The samples were also placed in circulating salt brines of varying pH as a supplementary corrosion testing mechanism to explore their corrosivity over extended time. Negligible weight change was experienced by the bare and coated steel samples over a period of 5 months. Increasing the coating thickness and the number of layers may provide higher resistance to uniform and localized corrosion.
\end{abstract}

Index Terms - spent nuclear fuel, nuclear waste canister, dry cask storage, electrochemical corrosion, corrosion, thin film coatings, passivity, activation

\section{INTRODUCTION}

Storage of spent nuclear fuel from commercial reactors is one of the most important issues facing the nuclear industry. Spent fuel is classified as high-level waste (HLW), which makes up more than 99\% of the total radioactivity contained in all forms of nuclear waste, and thus requires the most stringent control on performance of storage containers [1]. HLW storage containers are required to provide complete containment for up to 1000 years, after which very slow release of radionuclides is permitted, in accordance with NRC rule 10CFR60 [2,3]. On site dry cask storage is the only long term storage option for nuclear fuel removed from commercial light water reactors (LWRs). Dry storage casks consist primarily of a steel canister and concrete overpack, often with additional layers in between for neutron and gamma shielding [4].

HLW canisters are typically made of stainless steel because of its good mechanical strength and corrosion resistance stemming from its ability to readily form passive surface films $[1,5,6]$. Being an austenitic material, it is not susceptible to catastrophic brittle failure as are ferritic steels. However, stainless steel suffers from localized corrosion when exposed to various environments. By its nature, localized corrosion is random and volatile. Coupled with an overall lack of in-situ monitoring for HLW storage, the service life of the dry storage canisters is very difficult to predict.

The primary types of localized corrosion that plague stainless steel are intergranular corrosion and stress corrosion cracking (SCC), both of which have the potential to greatly shorten the useful life of spent fuel canisters. Chromium depletion due to carbide buildup at grain boundaries often leads to fissure via intergranular corrosion in stainless steels. This failure mechanism is a greater issue in the presence of ionizing radiation, which causes voids and cavities leading to further depletion of chromium along grain boundaries [7]. SCC is a method of crack initiation and/or growth involving a tensile stress of sufficient magnitude and an aggressive environment. For steel canisters, failure is most likely to occur through and near welded regions as they contain residual stresses from the welding process that are generally sufficient to cause SCC $[8,9]$. The principle environments causing localized corrosion in stainless steels are chloride-based due to chloride ions promoting pitting corrosion per localized passive film breakdown, which, when paired with the appropriate stress field, may lead to SCC [7]. Most of the environments to which waste canisters could potentially be exposed are chloride-containing (sea water, sea air, geological brines, etc.). Thus, chloride ions pose a threat to the long term integrity of HLW storage containers.

An alternative to stainless steels that has been considered and studied in the past is carbon steel. Carbon steel is known to corrode more readily than stainless steel but is more resistant to localized attack. Carbon steel lacks the ability to form full protective passive films under normal circumstances in most environments, which is the basis for the excellent corrosion resistance of stainless steel. However, localized corrosion is much more severe when a very protective surface layer is penetrated because the local attack can be sustained [10]. Owing to this, carbon steel is not generally plagued by localized corrosion, as is the bane of stainless steel. However, carbon steels are still susceptible to localized corrosion, particularly SCC in carbonate, nitrate, and caustic environments [3]. The residual stress can be mitigated with stress relief heat treatment such that SCC is not of great 
concern. This is seldom practical for stainless steels, as the threshold stress for SCC of carbon steels is much higher than for austenitic steels [11]. Moreover, SCC will typically not occur when there is significant uniform corrosion, as with carbon steel.

In order to combat premature failure of steel waste canisters, various thin-film inorganic coatings have been proposed. These coatings include $\mathrm{TiN}, \mathrm{ZrO}_{2}, \mathrm{TiO}_{2}, \mathrm{Al}_{2} \mathrm{O}_{3}$, and $\mathrm{MoS}_{2}$ and have been shown to be good barriers to localized corrosion and hydrogen diffusion [12,13].

In this study, these coatings are deposited on 1" diameter steel disks in single layers using non-reactive magnetron sputtering techniques. The oxide coatings $\left(\mathrm{ZrO}_{2}, \mathrm{TiO}_{2}\right.$, and $\left.\mathrm{Al}_{2} \mathrm{O}_{3}\right)$ deposit very slowly and have a maximum thickness below $100 \mathrm{~nm}$. The remaining nonoxide coatings (TiN and $\mathrm{MoS}_{2}$ ) can be deposited more quickly, resulting in a maximum thickness of approximately $500 \mathrm{~nm}$. Coating thicknesses have been measured using focused ion beam (FIB) milling techniques Stainless steel type 316 and 304, along with A36 low-alloy carbon steel with and without thin film coatings have been subjected to electrochemical polarization techniques and circulating salt brines in order to characterize uniform and localized corrosion, among other properties.

\section{THEORY}

\subsection{Electrochemical Corrosion}

Electrochemical measurements allow corrosion to be observed and quantified over a much shorter timescale than would be necessary in the absence of applied bias (polarization) and subsequent response current [14].

The Butler-Volmer (Eq. 1) is often used to describe the relationship between potential and current for a system undergoing a combination of anodic and cathodic electrochemical reactions. The quantity $2.3 \mathrm{RT} / \alpha \mathrm{nF}$ is customarily denoted as $\beta$ [15], in which case (1) may be rewritten as shown in (2). This gives a relationship between the applied current and the deviation from the equilibrium potential (overpotentail) in terms of parameters characteristic of the coupling of the material and environment (corrosion current and Tafel slopes).

$$
I=I_{\text {corr }}\left(\exp \left[\frac{\alpha_{a} n F\left(E-E_{\text {corr }}\right)}{R T}\right]-\exp \left[\frac{-\alpha_{c} n F\left(E-E_{\text {corr }}\right)}{R T}\right]\right)
$$

Where: $\alpha_{a}, \alpha_{c}$ are anodic and cathodic charge transfer coefficients

$\mathrm{F}$ is Faraday constant

$\mathrm{n}$ is the number of electrons involved in electrode reaction

$\mathrm{R}$ is the universal gas constant

$\mathrm{T}$ is absolute temperature, $\mathrm{K}$

$\mathrm{E}_{\text {corr }}$ is the corrosion (equilibrium) potential, $\mathrm{V}$
$\mathrm{E}$ is the potential, $\mathrm{V}$

$\mathrm{I}_{\text {corr }}$ is the corrosion (equilibrium) current, A

and

$\mathrm{I}$ is the current, A

$$
I=I_{a}+I_{c}=I_{\text {corr }}\left(e^{2.3 \eta / \beta_{a}}-e^{-2.3 \eta / \beta_{c}}\right)
$$

Where: $I_{a}, I_{c}$ are anodic and cathodic currents, A

$\eta$ is the overpotential $\left(\eta=E-E_{\text {corr }}\right), V$

$\beta_{\mathrm{a}}, \beta_{\mathrm{c}}$ are anodic and cathodic Tafel slopes, V/decade

By restricting the potential to a region very close to the corrosion or equilibrium potential (low overpotential region), the exponentials can be expanded in a Taylor series about $\eta=0$, resulting in the Stern-Geary equation [16]:

$$
\left.\frac{d \eta}{d I}\right|_{\eta \rightarrow 0}=\frac{\beta_{a} \beta_{c}}{2.3 I_{\text {corr }}\left(\beta_{a}+\beta_{c}\right)}
$$

The left hand side of (Eq. 3) is the slope of the potential versus current curve in the immediate vicinity of the equilibrium potential and is known as the polarization resistance, $R_{p}$.

In the high overpotential region, it is simple to show that either the anodic or cathodic reaction dominates. The region of high positive overpotential, $\eta>0$, is dominated by the anodic reaction, whereas in the high negative overpotential region, $\eta<0$, the cathodic reaction dominates. For anodic current (Eq. 4):

$$
I=I_{a}=\exp \left(\frac{2.3 \eta}{\beta_{a}}\right)
$$

Rearranging (Eq. 4), the overpotential can be written as:

$$
\eta=a+b \log (I)=\frac{\beta_{a}}{2.3}\left[\ln (I)-\ln \left(I_{\text {corr }}\right)\right]
$$

Therefore, the anodic Tafel coefficient, $\beta_{\mathrm{a}}$, is proportional to the slope of the voltage versus log current curve in the region of positive overpotential. The same applies for the cathodic Tafel coefficient, $\beta_{c}$, in the negative overpotential region.

Rearranging (Eq. 3) to solve for corrosion current gives:

$$
I_{\text {corr }}=\frac{\beta_{a} \beta_{c}}{2.3 R_{p}\left(\beta_{a}+\beta_{c}\right)}
$$

All terms on the right hand side of (Eq. 6) can be determined experimentally, in which case the equilibrium current is immediately obtainable. Once the corrosion current has been calculated, (Eq. 7) can be used to relate 
corrosion current to corrosion rate for a given material undergoing electrochemical corrosion.

$$
C R=\frac{I_{\text {corr }} \cdot K \cdot E W}{\rho \cdot A}
$$

Where: $\rho$ is the mass density, $\mathrm{g} / \mathrm{cm}^{3}$

EW is the equivalent weight of sample (g)

$\mathrm{A}$ is the area exposed to solution, $\mathrm{cm}^{2}$

$\mathrm{K}$ is a constant (= $3272 \mathrm{~mm} / \mathrm{A}$-cm-year)

$\mathrm{CR}$ is the corrosion rate, $\mathrm{mm}$ per year (mmpy)

\subsection{Kinetic Activation}

The corrosion current (or corrosion rate) has been shown to follow an Arrhenius relationship (Eq. 8) with temperature [17-19]:

$$
j_{\text {corr }}=A \cdot \exp \left(\frac{-E_{a}^{0}}{R T}\right)
$$

where: $\mathrm{j}_{\text {corr }}$ is the corrosion current density $\left(\mu \mathrm{A} / \mathrm{cm}^{2}\right)$,

$\mathrm{A}$ is the pre-exponential factor $\left(\mu \mathrm{A} / \mathrm{cm}^{2}\right)$,

$\mathrm{E}_{\mathrm{a}}{ }^{0}$ is the apparent activation energy $(\mathrm{kJ} / \mathrm{mol})$,

$\mathrm{R}$ is the ideal gas constant,

and $\quad \mathrm{T}$ is the absolute pressure $(\mathrm{K})$.

A larger activation energy is indicative of a higher energy barrier for corrosion to occur [20]. The activated, or transition state, complex can be formed faster and easier for smaller activation energies. The apparent activation energy has been shown to decrease as the concentration of acid in the corrosion solution increases [21]. This further supports that the activation energy represents an energy barrier to corrosion.

Alternatively, a more appropriate relationship between corrosion rate and temperature may be expressed using the Eyring equation derived from transition state theory (Eq. 9) [20-22]:

$$
j_{\text {corr }}=\frac{R T}{N_{a} h} \exp \left(\frac{\Delta S_{a}^{0}}{R}\right) \exp \left(\frac{-\Delta H_{a}^{0}}{R T}\right)
$$

where: $\mathrm{N}_{\mathrm{a}}$ is Avogadro's number,

$\mathrm{h}$ is Plank's constant,

and $\Delta \mathrm{S}_{\mathrm{a}}{ }^{0}$ and $\Delta \mathrm{H}_{\mathrm{a}}{ }^{0}$ are entropy and enthalpy of activation, respectively.

Equation 9 encompasses the fact that the activation energy may be misleading if significant reordering occurs during the corrosion process such that entropy is large. It also provides a more complete relationship between corrosion rate and temperature, as it accounts for the total free energy, and the pre-exponential factor is not empirical, as in (Eq. 8). Equation 9 may be rewritten in order to determine the activation enthalpy and entropy from the slope and intercept of a line fit to $\ln \left(\mathrm{j}_{\text {corr }} / \mathrm{T}\right)$ versus the reciprocal of temperature, as shown by (Eq.10):

$$
\ln \left(\frac{j_{\text {corr }}}{T}\right)=\left[\ln \left(\frac{R}{N_{a} h}\right)+\frac{\Delta S_{a}^{0}}{R}\right]-\left(\frac{\Delta H_{a}^{0}}{R}\right) \frac{1}{T}
$$

The Gibbs free energy of the corroding system can be calculated from the entropy and enthalpy:

$$
\Delta G=\Delta H-T \Delta S
$$

Kinetic properties are typically used to describe corrosion in the presence of an inhibitor [17,19-21]. Whereas there is no inhibitor dissolved in the testing solution, the coatings themselves may be considered to function as inhibitors. The coverage of the steel surface by the coatings could influence the corrosion rate, as is typically the case with inhibitors. Transition state theory has also been applied to describe corrosion in the presence of oxide films on metals [22], representing the primary corrosion resistance of stainless steel.

\subsection{Passivity and Passive Breakdown}

The primary resistance to corrosion for many materials stems from the ability to form passive films. For stainless steel, the principle thin film formed in corrosive environments is a combination of chromium (III) oxide $\left(\mathrm{Cr}_{2} \mathrm{O}_{3}\right)$ and iron (III) oxide $\left(\mathrm{Fe}_{2} \mathrm{O}_{3}\right)$. The passive film inhibits corrosion of the substrate, even in aggressive environments.

The breakdown of the passive film is linked with localized corrosion and materializes as a much larger increase in current as applied potential increases. The potential at which the passive film is interrupted has been associated with the critical pitting potential, or the potential at which pits or holes form and begin to propagate [23,24]. Passive breakdown in chloridecontaining media occurs when chloride ions interact with the passive film causing Schottky defect pairs to form. If cations from the metal surface are unable to consume vacancies at a sufficient rate, voids will cause local detachment or rupture of the passive film $[25,26]$. Thus, passive breakdown is controlled by vacancy diffusion, and the Arrhenius-type behavior of the breakdown potential is intuitive (Eq. 12). The breakdown potential may be associated with an activation energy that is congruent to the activation energy for vacancy formation and diffusion.

$$
\eta_{B D}=C \cdot \exp \left(\frac{-E_{a}^{0}}{R T}\right)
$$

Where: $\eta_{\mathrm{BD}}$ is the breakdown overpotential, $\mathrm{V}$ 
$\mathrm{C}$ is the pre-exponential factor

and $\quad E_{a}{ }^{0}$ is the activation energy for passive breakdown, $\mathrm{kJ} / \mathrm{mol}$.

\section{EXPERIMENTAL METHODS}

\subsection{Electrochemical Corrosion}

Electrochemical testing was completed using the MULTIPORT $^{\mathrm{TM}}$ corrosion cell kit and Interface 1000 potentiostat from Gamry Instruments, along with the DC105 electrochem software. A standard three electrode setup with a graphite counter electrode and saturated $\mathrm{Ag} / \mathrm{AgCl}$ reference electrode is used. The reference electrode is placed directly in the corrosion cell to avoid problems posed by a salt bridge. The samples are placed in a holder conducive to testing disks of varying thickness, such that the total exposed surface area to the aerated $1 \mathrm{M}$ $\mathrm{NaCl}$ solution is $4.15 \mathrm{~cm}^{2}$.

Prior to testing, the stainless steel samples are immersed in the testing solution for 15 to 24 hours, allowing the open circuit potential to stabilize. Carbon steel samples equilibrate much more rapidly and need only be placed in solution 1-3 hours before testing. Temperature is controlled using a water bath and thermocouple placed inside the corrosion cell. Voltage drop due to resistance of the $\mathrm{NaCl}$ solution is accounted for by the software controlling the potentiostat using the current-interrupt method [27].

Cyclic potentiodynamic polarization curves are measured for each sample to determine corrosion rate and passivation capabilities. These curves encompass both high and low overpotential regions and thus can provide corrosion rates without additional testing. The data gathered can be used for quantitative analysis provided the voltage scan rate is slow. The scan rate used for all electrochemical analysis presented here is $0.6 \mathrm{~V} / \mathrm{hr}(0.1667$ $\mathrm{mV} / \mathrm{s}$ ), in accordance with ASTM standard G61-86 [28]. The forward voltage scan is measured from $250 \mathrm{mV}$ below the open circuit potential $\left(\mathrm{E}_{\mathrm{oc}}\right)$ to $1.2 \mathrm{~V}$ above $\mathrm{E}_{\mathrm{oc}}$, or until a critical current density is reached. The reverse scan begins immediately following the forward scan and proceeds at the same scan rate. The reverse scan determines the localized corrosion behavior in the form of a hysteresis in the voltage-current relationship. These tests are completed at temperatures of $20,40,60$, and $80^{\circ} \mathrm{C}$ to simulate elevated canister temperatures due to decay heat.

Slopes of the anodic and cathodic half reactions are determined separately from the Echem Analyst ${ }^{\mathrm{TM}}$ software from Gamry Instruments, using an 'E log I' fit within 250 $\mathrm{mV}$ of the corrosion potential (high overpotential region), which is the region in which (Eq. 5) applies. Polarization resistance is then calculated by extracting the data within the low overpotential region $\left( \pm 5 \mathrm{mV}\right.$ from $\left.E_{\text {corr }}\right)$ and performing a linear regression. $\mathrm{R}_{\mathrm{p}}$ is established as the slope of this line. From this, Eqs. (6) and (7) are used to compute the corrosion current and corrosion rate. Several samples of each material at each of the four temperatures are tested; the values of corrosion current presented are averages.

The $\mathrm{MoS}_{2}$ coatings suffered from adhesion issues and thus are not included in this paper.

\subsection{Corrosion in Circulating Salt Brines}

As an additional source of corrosion testing, bare and coated steel samples have been placed in circulators with brines of different $\mathrm{pH}$ for as long as 150 days. The mass of each sample is measured at regular intervals to determine the change in weight due to corrosion. The composition of the corrosive solutions is given in Table I.

Table I: Composition of simulated concentrated water solutions

\begin{tabular}{|l|l|l|l|l|l|}
\hline \multicolumn{2}{|c|}{ PH $=2.4$} & \multicolumn{3}{c|}{ PH $=8.2$} & \multicolumn{2}{c|}{ PH= 13.15 } \\
\hline Compound & Quantity & Compound & Quantity & Compound & Quantity \\
\hline $\mathrm{H}_{2} \mathrm{O}$ & $1000 \mathrm{~mL}$ & $\mathrm{H}_{2} \mathrm{O}$ & $800 \mathrm{ml}$ & $\mathrm{H}_{2} \mathrm{O}$ & $800 \mathrm{ml}$ \\
$\mathrm{NaCl}$ & $70 \mathrm{~g}$ & $\mathrm{KCl}$ & $120 \mathrm{~g}$ & $\mathrm{KCl}$ & $90 \mathrm{~g}$ \\
$\mathrm{KCl}$ & $70 \mathrm{~g}$ & $\mathrm{Na}_{2} \mathrm{SO}_{4}$ & $20 \mathrm{~g}$ & $\mathrm{NaCl}$ & $80 \mathrm{~g}$ \\
$\mathrm{KNO}_{3}$ & $15 \mathrm{~g}$ & $\mathrm{NaCl}$ & $90 \mathrm{~g}$ & $\mathrm{Na}_{2} \mathrm{SO}_{4}$ & $15 \mathrm{~g}$ \\
$\mathrm{MgSO}_{4}$ & $15 \mathrm{~g}$ & $\mathrm{MgSO}_{4}$ & $30 \mathrm{~g}$ & $\mathrm{NaOH}$ & $20 \mathrm{ml}$ \\
$\mathrm{NaOH}^{\mathrm{NaO}}$ & $5 \mathrm{~mL}$ & $\mathrm{KNO}_{3}$ & $15 \mathrm{~g}$ & & \\
$\mathrm{H}_{2} \mathrm{SO}_{4}$ & $3 \mathrm{~mL}$ & & & & \\
\hline
\end{tabular}

Bare and coated stainless steel samples showed no weight change over a 150-day period in any of the three solutions, and coatings are still intact. This confirms good corrosion resistance and good adhesion of protective coatings. No signs of pit initiation in any bare or coated stainless steel samples were observed.

Carbon steel samples saw measurable corrosion in all solutions, with up to $3 \%$ weight loss after 5 months. Corrosion in the low $\mathrm{pH}$ solution was highest, as sulfuric acid makes for an aggressive solution.

\section{Results and Discussion}

\subsection{Corrosion Rate}

Average corrosion current density versus temperature is plotted in Figures 1-3 for bare and singly-coated steels in $1 \mathrm{M} \mathrm{NaCl}$. Corrosion current (Eq. 6) is more indicative of corrosive behavior than the corrosion rate calculated in (Eq. 7). Proper calculation of the corrosion rate requires an appropriate mass density and equivalent weight of the corroding surface. This can be ambiguous with porous coatings of sub-micron thickness because the coating material and steel substrate together constitute the corrosion system. Determining the mass density and equivalent weight requires knowledge of the maximum 
depth from which ions from the steel could reach the surface and desorb into solution. Instead, corrosion current can be calculated with no material properties and better represents the propensity for the material to corrode in a given solution.

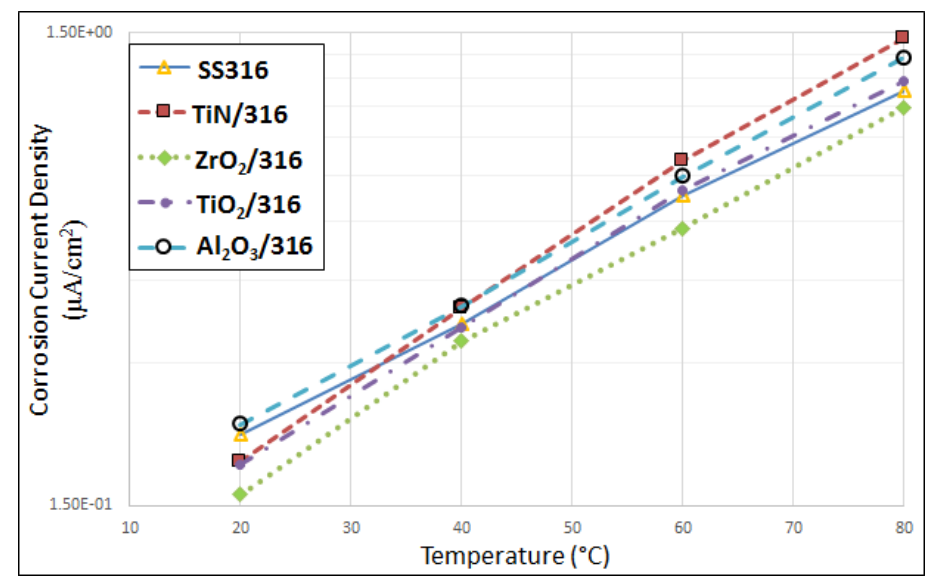

Figure 1: Corrosion current density vs. temperature - stainless steel type 316 (log scale)

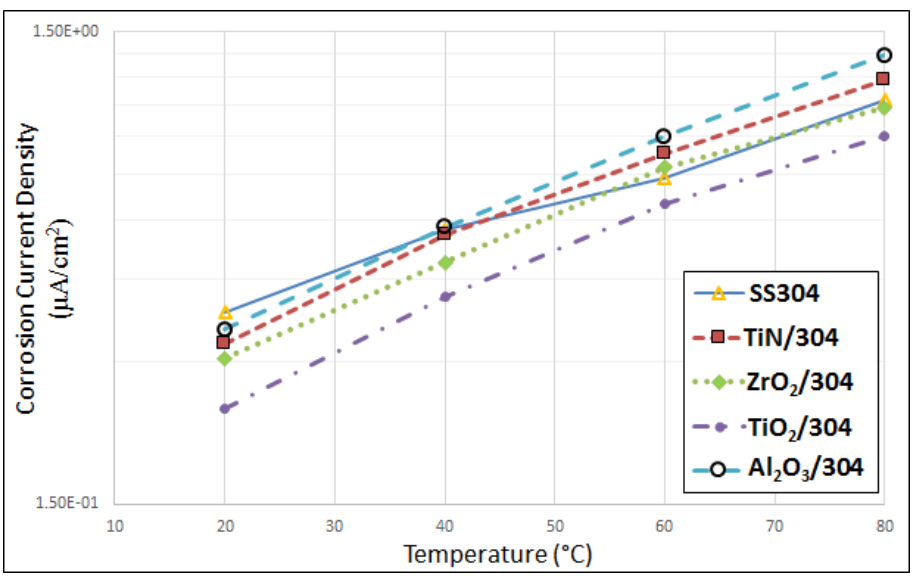

Figure 2: Corrosion current density vs. temperature - stainless steel type 304 (log scale)

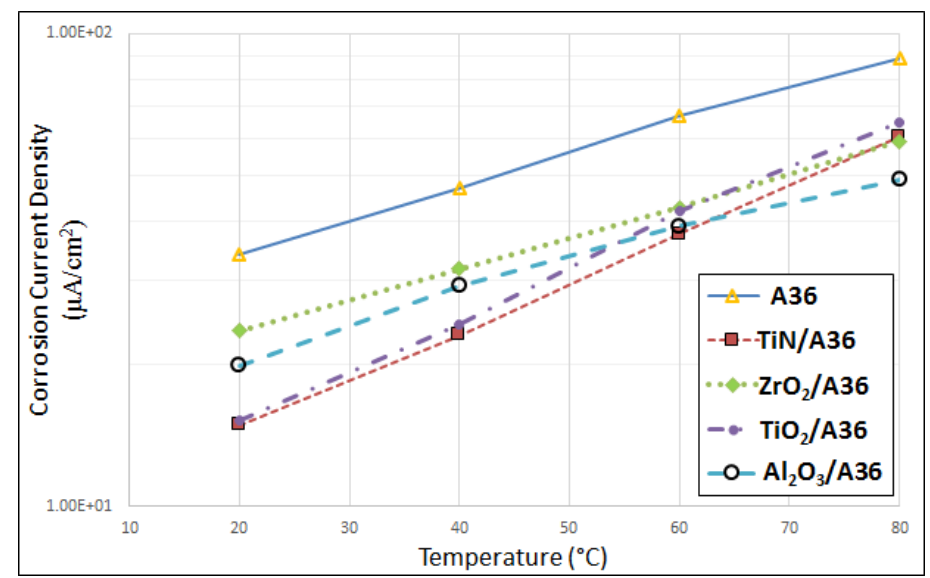

Figure 3: Corrosion current density vs. temperature - A36 carbon steel (log scale)

The values of corrosion current for the coated steels are quite similar to the bare steel, suggesting that the steel substrate is corroding along with the surface coatings. Considering that the coatings are thin (most are less than
$100 \mathrm{~nm}$ thick), it is likely that the coatings are porous, causing ions from both the substrate and coating to flow into the solution. However, the coated samples also do not show significantly higher corrosion rates, indicating that corrosion is not enhanced by placing a more noble metal in contact with steel.

Carbon steel samples show corrosion currents several orders of magnitude larger than stainless steel. This is expected, as A36 steel lacks $\mathrm{Ni}$ and $\mathrm{Cr}$, which are essential to the corrosion resistances exhibited by type 304 and 316 stainless steels. Figure 3 shows that the coated samples have consistently lower corrosion rates than the bare carbon steel. This signifies that the coatings may be able to protect carbon steel, which corrodes more readily than stainless, if the thickness and number of coating layers increases.

\subsection{Kinetic Activation}

Figures 4-6 show the logarithm of the corrosion current density divided by absolute temperature, $\ln \left(\mathrm{j}_{\text {corr }} / \mathrm{T}\right)$, versus the inverse of absolute temperature. The materials tested show linear trends, in accordance with (Eq. 10), displaying the activation-type behavior of the materials tested.

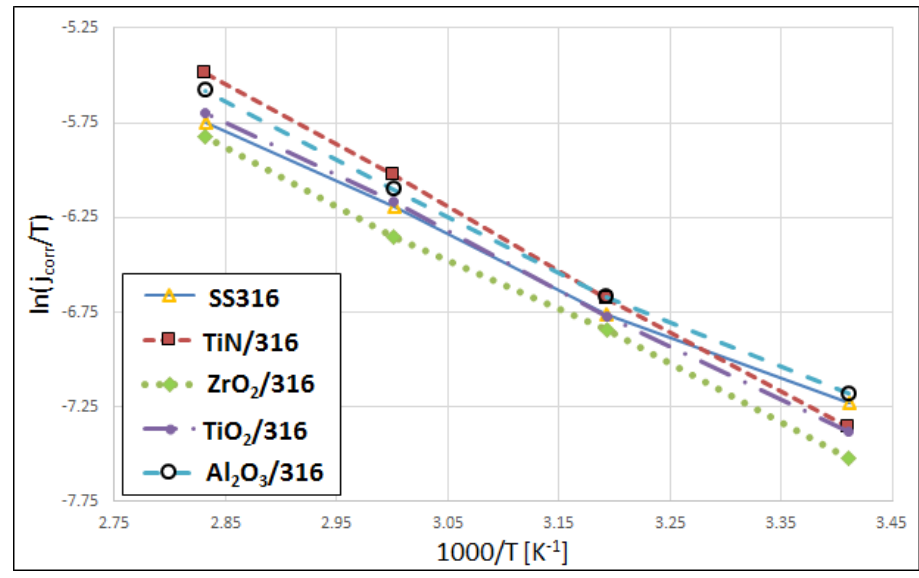

Figure 4: Activation kinetics: application of the Eyring equation for SS type 316 


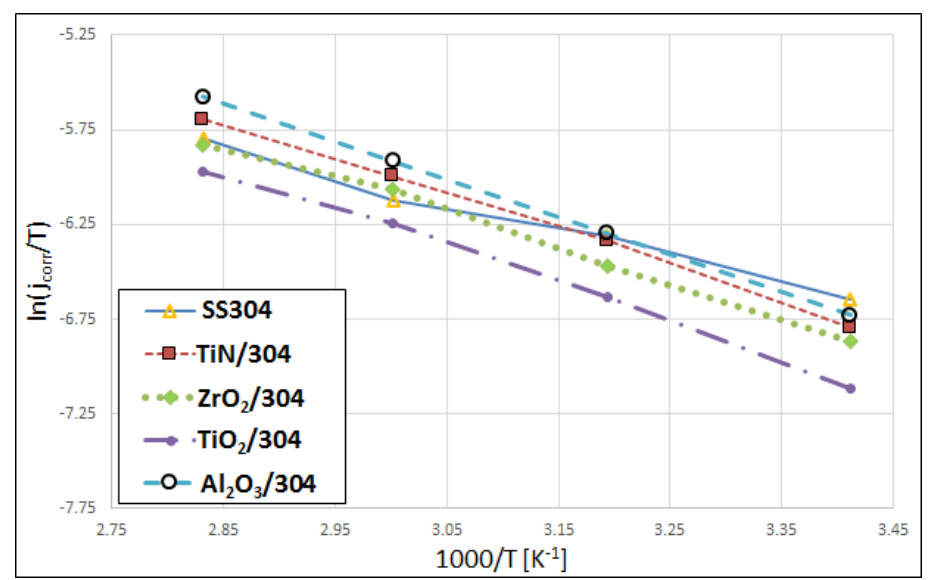

Figure 5: Activation kinetics: application of the Eyring equation for SS type 304

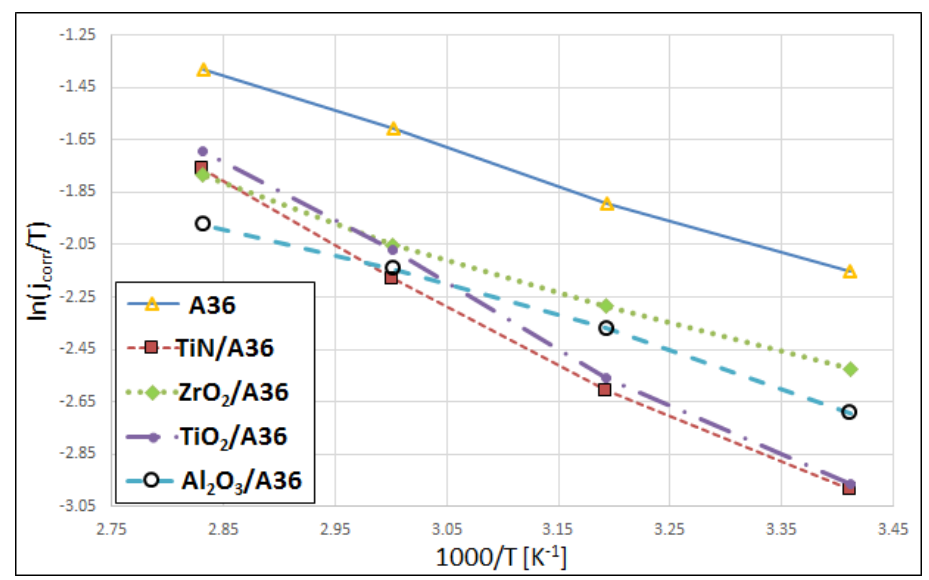

Figure 6: Activation kinetics: application of the Eyring equation for A36 carbon steel

The kinetic parameters computed using (Eqs. 8 \& 9) are presented in Tables II-IV for the materials studied in aerated $1 \mathrm{M} \mathrm{NaCl}$. Ln(A) is the natural logarithm of the pre-exponential factor in (Eq. 8) and $\mathrm{E}_{\mathrm{a}}, \mathrm{H}_{\mathrm{a}}$, and $\mathrm{S}_{\mathrm{a}}$, are the activation energy, enthalpy, and entropy, respectively. The standard deviations are calculated using uncertainty propagation assuming independent (or non-correlated) variables and represent uncertainties arising from the spread in experimental data and from the linear regression.

Table II: Activation parameters - SS316

\begin{tabular}{|c|c|c|c|c|c|}
\hline Material & $\mathbf{L n}(\mathbf{A})$ & $\begin{array}{c}\mathbf{E}_{\mathbf{a}}(\mathbf{k J} / \\
\mathbf{m o l})\end{array}$ & $\begin{array}{c}\mathbf{H}_{\mathbf{a}}(\mathbf{k J} \\
/ \mathbf{m o l})\end{array}$ & $\begin{array}{c}\mathbf{S}_{\mathbf{a}}(\mathbf{k J} / \\
\mathbf{m o l})\end{array}$ & $\mathbf{E}_{\mathbf{a}}-\mathbf{H}_{\mathbf{a}}$ \\
\hline $\mathrm{SS} 316$ & 8.37 & $\begin{array}{c}24.27 \pm \\
4.09\end{array}$ & $\begin{array}{c}21.6 \pm \\
4.08\end{array}$ & $\begin{array}{c}-184.28 \\
\pm 13.06\end{array}$ & 2.67 \\
\hline $\mathrm{TiN} / 316$ & 10.48 & $\begin{array}{c}29.65 \pm \\
11.32\end{array}$ & $\begin{array}{c}26.98 \pm \\
11.5\end{array}$ & $\begin{array}{c}-166.79 \\
\pm 35.3\end{array}$ & 2.67 \\
\hline \multirow{2}{*}{$\mathrm{ZrO}_{2} / 316$} & 9.15 & $\begin{array}{c}26.76 \pm \\
2.95\end{array}$ & $\begin{array}{c}24.09 \pm \\
2.95\end{array}$ & $\begin{array}{c}-177.83 \\
\pm 9.45\end{array}$ & 2.67 \\
\hline \multirow{2}{*}{$\mathrm{TiO}_{2} / 316$} & 9.38 & $\begin{array}{c}27.02 \pm \\
4.47\end{array}$ & $\begin{array}{c}24.35 \pm \\
4.47\end{array}$ & $\begin{array}{c}-171.91 \\
\pm 11.8\end{array}$ & 2.67 \\
\hline \multirow{2}{*}{$\mathrm{Al}_{2} \mathrm{O}_{3} / 316$} & 9.01 & $\begin{array}{c}25.72 \pm \\
5.12\end{array}$ & $\begin{array}{c}23.05 \pm \\
5.11\end{array}$ & $\begin{array}{c}-186.46 \\
\pm 10.2\end{array}$ & 2.67 \\
\hline
\end{tabular}

Table III: Activation parameters - SS304

\begin{tabular}{|c|c|c|c|c|c|}
\hline Material & $\mathbf{L n}(\mathbf{A})$ & $\begin{array}{c}\mathbf{E}_{\mathbf{a}}(\mathbf{k J} / \\
\mathbf{m o l})\end{array}$ & $\begin{array}{c}\mathbf{H}_{\mathbf{a}}(\mathbf{k J} \\
/ \mathbf{m o l})\end{array}$ & $\begin{array}{c}\mathbf{S}_{\mathbf{a}}(\mathbf{k J} / \\
\mathbf{m o l})\end{array}$ & $\mathbf{E}_{\mathbf{a}}-\mathbf{H}_{\mathbf{a}}$ \\
\hline $\mathrm{SS} 304$ & 4.96 & $\begin{array}{c}14.45 \pm \\
4.85\end{array}$ & $\begin{array}{c}11.78 \pm \\
4.85\end{array}$ & $\begin{array}{c}-212.61 \\
\pm 15.39\end{array}$ & 2.67 \\
\hline $\mathrm{TiN} / 304$ & 6.44 & $\begin{array}{c}18.38 \pm \\
5.74\end{array}$ & $\begin{array}{c}15.71 \pm \\
5.74\end{array}$ & $\begin{array}{c}-200.3 \pm \\
17.99\end{array}$ & 2.67 \\
\hline $\mathrm{ZrO}_{2} / 304$ & 6.13 & $\begin{array}{c}17.82 \pm \\
4.15\end{array}$ & $\begin{array}{c}15.15 \pm \\
4.15\end{array}$ & $\begin{array}{c}-202.88 \\
\pm 13.18\end{array}$ & 2.67 \\
\hline $\mathrm{TiO}_{2} / 304$ & 6.47 & $\begin{array}{c}19.2 \pm \\
5.63\end{array}$ & $\begin{array}{c}16.54 \pm \\
5.63\end{array}$ & $\begin{array}{c}-200.1 \pm \\
17.72\end{array}$ & 2.67 \\
\hline $\mathrm{Al}_{2} \mathrm{O}_{3} / 304$ & 6.83 & $\begin{array}{c}19.19 \pm \\
4.37\end{array}$ & $\begin{array}{c}16.52 \pm \\
4.37\end{array}$ & $\begin{array}{c}-197.12 \\
\pm 13.62\end{array}$ & 2.67 \\
\hline
\end{tabular}

Table IV: Activation parameters - A36

\begin{tabular}{|c|c|c|c|c|c|}
\hline Material & $\mathbf{L n}(\mathrm{A})$ & $\begin{array}{c}\mathbf{E}_{\mathbf{a}} \mathbf{( k J} / \\
\mathbf{m o l})\end{array}$ & $\begin{array}{c}\mathbf{H}_{\mathbf{a}}(\mathbf{k J} \\
/ \mathbf{m o l})\end{array}$ & $\begin{array}{c}\mathbf{S}_{\mathbf{a}}(\mathbf{k J} / \\
\mathbf{m o l})\end{array}$ & $\mathbf{E}_{\mathbf{a}}-\mathbf{H}_{\mathbf{a}}$ \\
\hline $\mathrm{A} 36$ & 9.2 & $\begin{array}{c}13.85 \pm \\
6.53\end{array}$ & $\begin{array}{c}11.18 \pm \\
6.53\end{array}$ & $\begin{array}{c}-177.41 \pm \\
20.36\end{array}$ & 2.67 \\
\hline $\mathrm{TiN} / \mathrm{A} 36$ & 10.95 & $\begin{array}{c}20.21 \pm \\
6.58\end{array}$ & $\begin{array}{c}17.55 \pm \\
6.57\end{array}$ & $\begin{array}{c}-162.82 \pm \\
20.72\end{array}$ & 2.67 \\
\hline $\mathrm{ZrO}_{2} / \mathrm{A} 36$ & 8.54 & $\begin{array}{c}13.17 \pm \\
6.65\end{array}$ & $\begin{array}{c}10.51 \pm \\
6.65\end{array}$ & $\begin{array}{c}-182.86 \pm \\
20.8\end{array}$ & 2.67 \\
\hline $\mathrm{TiO}_{2} / \mathrm{A} 36$ & 11.35 & $\begin{array}{c}21.12 \pm \\
6.41\end{array}$ & $\begin{array}{c}18.45 \pm \\
6.41\end{array}$ & $\begin{array}{c}-159.46 \pm \\
20.12\end{array}$ & 2.67 \\
\hline $\mathrm{Al}_{2} \mathrm{O}_{3} / \mathrm{A} 36$ & 8.35 & $\begin{array}{c}13.02 \pm \\
3.68\end{array}$ & $\begin{array}{c}10.35 \pm \\
3.68\end{array}$ & $\begin{array}{c}-184.42 \pm \\
11.69\end{array}$ & 2.67 \\
\hline
\end{tabular}

Positive values of enthalpy and apparent activation energy reflect the endothermic nature of the dissolution process. Negative entropy values represent that the activated complex is in a more ordered state relative to the initial state. In other words, the system becomes less chaotic as corrosion occurs.

The activation energy and enthalpy are seen to behave according to the following equation, which stems from comparison of the Arrhenius (Eq. 8) and Eyring (Eq. 9) equations for activation:

$$
E_{a}-H_{a}=R T
$$

Where: $\quad E_{a}$ is the apparent activation energy, $\mathrm{kJ} / \mathrm{mol}$, and $\mathrm{H}_{\mathrm{a}}$ is the enthalpy of activation, $\mathrm{kJ} / \mathrm{mol}$.

$\mathrm{E}_{\mathrm{a}}-\mathrm{H}_{\mathrm{a}}=2.67 \mathrm{~kJ} / \mathrm{mol}$ for each material, and the average of RT over the applicable temperature range is $2.69 \mathrm{~kJ} / \mathrm{mol}$. This confirms that the corrosion process is a unimolecular reaction with a single transition state [29].

All coating materials on both types of stainless steel have activation energies (and enthalpies) that are within one standard deviation of each other. Both bare steels show markedly lower activation energy than their coated counterparts but still lie within statistical significance. This difference may become more significant as coating thickness increases and multilayer coatings are introduced, resulting in better corrosion resistance. 
Coating materials on A36 steel show two distinct slopes in Figure 6. Titanium-containing compounds (TiN and $\mathrm{TiO}_{2}$ ) have activation energy of approximately 20 $\mathrm{kJ} / \mathrm{mol}$, whereas the remaining oxide compounds $\left(\mathrm{ZrO}_{2}\right.$ and $\mathrm{Al}_{2} \mathrm{O}_{3}$ ) exhibit activation energy hovering around 13 $\mathrm{kJ} / \mathrm{mol}$. Bare A36 steel also has an activation energy slightly above $13 \mathrm{~kJ} / \mathrm{mol}$, demonstrating that zirconia and alumina may not provide the same level of protection from corrosion as the titanium compounds. However, the oxide coatings are all under $100 \mathrm{~nm}$ thick, so increasing thickness of the coating will likely change corrosion resistance properties.

Both bare and coated stainless steels type 316 and 304 have very similar values of Gibbs free energy. This indicates analogous corrosion behavior among the samples tested, as shown in Figures 1 and 2. These values are lower for the A36 carbon steel, which is natural because a larger Gibbs free energy represents better resistance to corrosion as temperature increases. Differences in free energy among coating materials are well within standard deviation.

\subsection{Passivity}

The capacity for passivation can be determined from cyclic polarization curves, examples of which are shown in Figures 7-9. The passive region is defined by a small change in current over a large potential range. This corresponds to a near-vertical line on the cyclic polarization curves. All of the materials studied show decreased passivity, in the form of a smaller passive region, with increasing temperature, as expected. Raising the temperature enhances the diffusion of oxygen and $\mathrm{Cl}^{-}$ ions, increasing the likelihood for passive film breakdown and pitting. In most cases, passivity is nonexistent at $80^{\circ} \mathrm{C}$, showing that temperature has a significant effect on corrosion resistance.

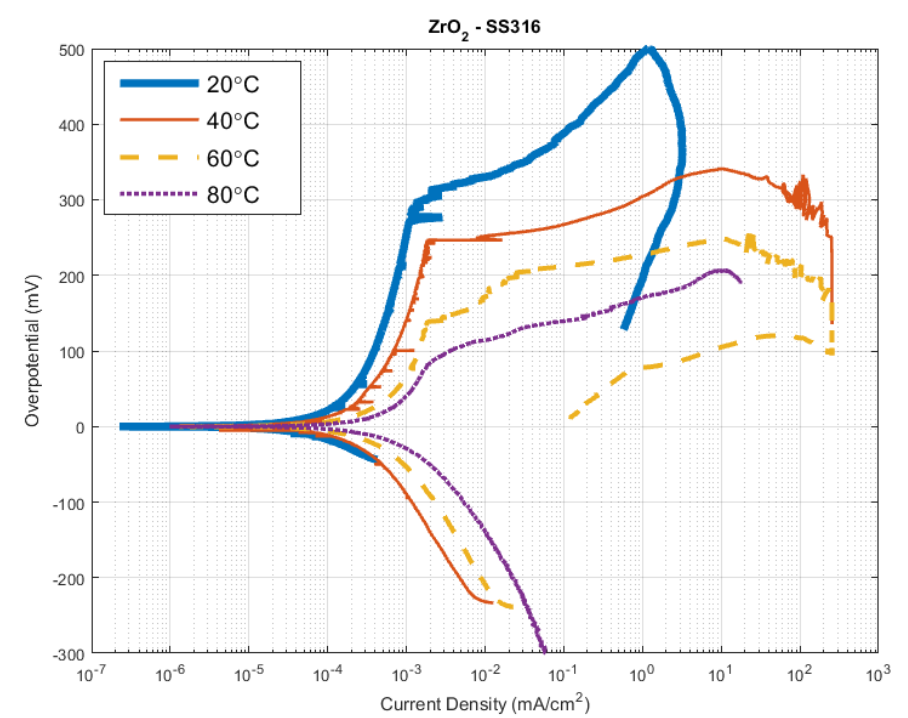

Figure 7: Cyclic polarization curves - $\mathrm{ZrO}_{2}$ - SS316

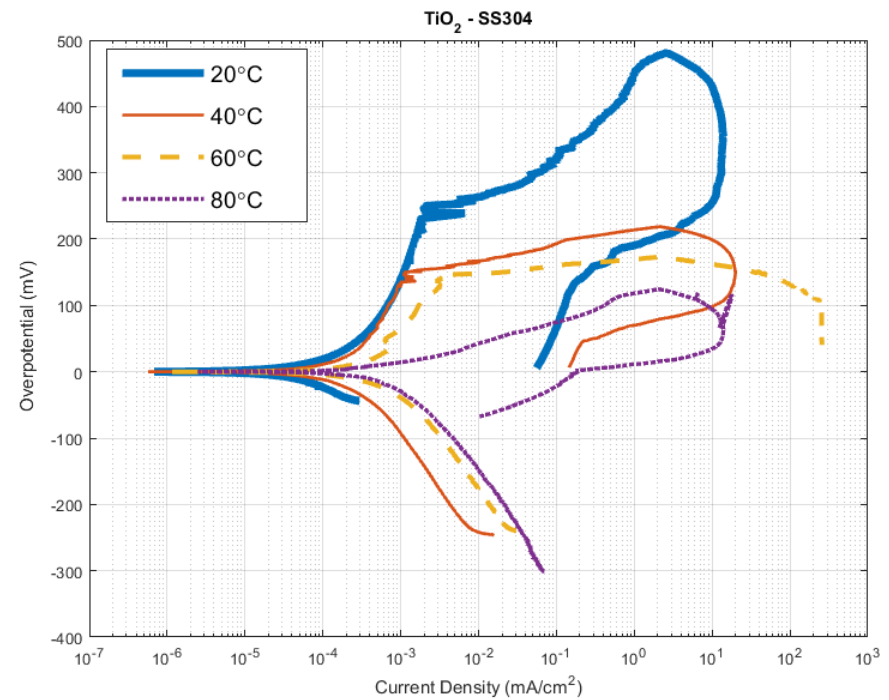

Figure 8: Cyclic polarization curves - $\mathrm{TiO}_{2}$ - SS304

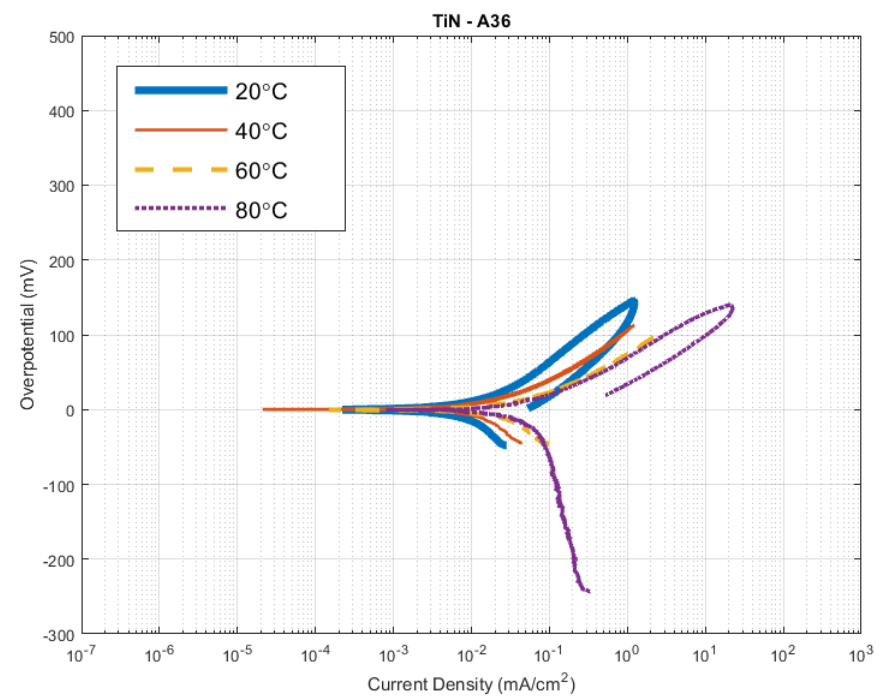

Figure 9: Cyclic polarization curves - TiN - A36

The hysteresis in the polarization curve during the reverse scan is indicative of localized corrosion. In the absence of pitting or crevice corrosion, the reverse scan loop would lie nearly on top of the curve from the forward scan. The shape of the cyclic polarization curves is the same for all coatings, suggesting similar corrosion mechanisms. This likely indicates that all samples are dominated by the steel substrate regardless of the coating material.

The A36 steel exhibits no discernible passivity because it corrodes uniformly at a much higher rate than stainless steel. Most iron oxide films that form on the surface are readily dissolved by corrosion on the surface of the metal. Iron (and low-alloy steels) is capable of passivating at very high current density $\left(\sim 1-10 \mathrm{~A} / \mathrm{cm}^{2}\right)$ Current above $1 \mathrm{~A}$ cannot be measured by the potentiostat in use; current densities were kept well below the supposed critical values for iron passivation. Thus, no passive behavior was observed for A36 carbon steel. However, not forming a significant passive film means no 
breakdown and limited localized corrosion. The cyclic polarization curves for A36 show very little hysteresis, indicative of minimal pitting or crevice corrosion. The corrosion of carbon steel is quite predictable in what seems to be the absence of significant localized corrosion. Although carbon steel would require thicker containers to account for steady corrosion, it is not nearly as susceptible to SCC and pitting, which are the primary downfalls of stainless steel. Having a predictable service life may be of interest, especially in nuclear waste storage.

The critical pitting (or breakdown) potential can be used as a measure of the passive capabilities of a material. A larger overpotential for initiation of pitting characterizes more desirable passive behavior. A majority of bare and coated stainless steel samples showed signs of crevice corrosion at points of contact with the sample holder. It is suspected that a portion of the hysteresis in the polarization curves is due to this crevice corrosion, which occurs following interruption of the passive film. The passive breakdown voltage cannot be linked to the critical pitting potential until crevice corrosion is eliminated. Rather, the breakdown voltage marks the onset of localized attack, including pitting and crevice corrosion.

Similarly to the corrosion current density, experimental values of breakdown overpotential show an exponential relationship with temperature. The materials tested have exponentially smaller passive regions as the temperature increases. The behavior of passive breakdown overvoltage with temperature is displayed in Figures 10 and 11 , and the logarithm of breakdown overvoltage ( $\left.\eta_{\mathrm{BD}}\right)$ versus inverse temperature can be fit to a straight line. Activation energies calculated from (Eq. 12) are given in Table V for bare and coated stainless steel. Carbon steel is omitted because it displayed no discernible passivity and thus no passive breakdown.

Both stainless steels and each coating material exhibits very similar breakdown behavior. The activation energies are all nearly identical within the confidence range. The alumina coatings on both steels are outliers in terms of apparent activation energy. The activation energy for the alumina coating on the 316 stainless steel is lower than expected, and is higher than expected on the 304 stainless steel. The true value is likely between these two extremes, considering the corrosion behavior and shape of the cyclic polarization curves for alumina coatings was identical to those of the other materials.

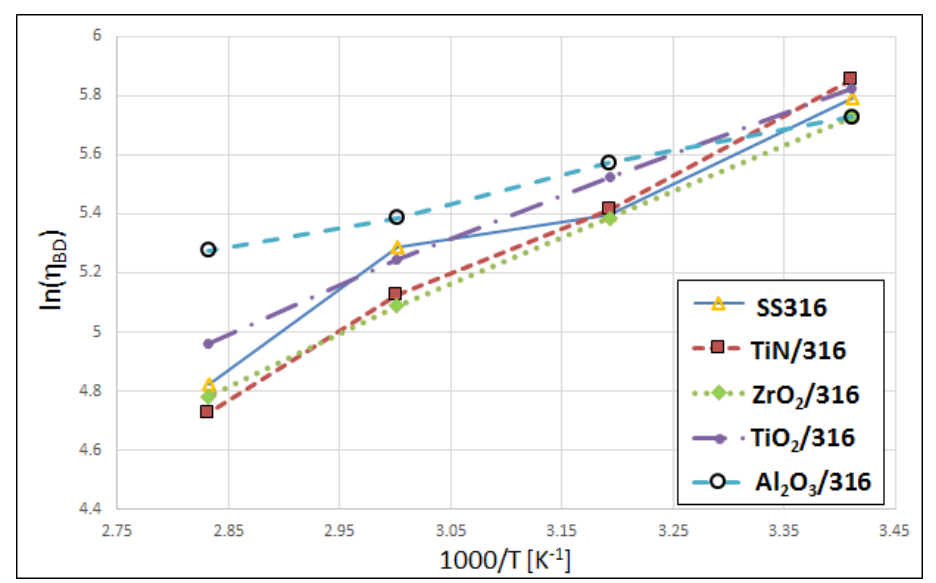

Figure 10: Breakdown overvoltage vs. temperature - SS316

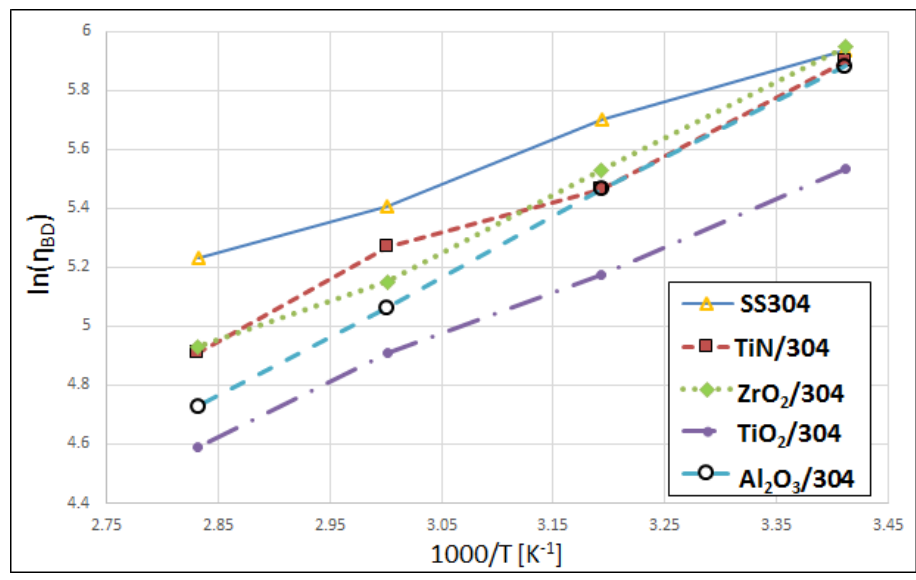

Figure 11: Breakdown overvoltage vs temperature - SS304

Table V: Apparent Activation Energy for Passive Breakdown of Stainless Steel

\begin{tabular}{|c|c|c|c|}
\hline Material & $\mathbf{E}_{\mathbf{a}}(\mathbf{k J} / \mathbf{m o l})$ & Material & $\left.\mathbf{E}_{\mathbf{a}} \mathbf{( k J} / \mathbf{m o l}\right)$ \\
\hline $\mathrm{SS} 316$ & $12.93 \pm 7.04$ & $\mathrm{SS} 304$ & $10.35 \pm 1.6$ \\
\hline $\mathrm{TiN} / 316$ & $15.82 \pm 2.6$ & $\mathrm{TiN} / 304$ & $13.65 \pm 2.21$ \\
\hline $\mathrm{ZrO}_{2} / 316$ & $13.49 \pm 5.44$ & $\mathrm{ZrO}_{2} / 304$ & $14.83 \pm 5.86$ \\
\hline $\mathrm{TiO}_{2} / 316$ & $12.38 \pm 3.25$ & $\mathrm{TiO}_{2} / 304$ & $13.35 \pm 3.58$ \\
\hline $\mathrm{Al}_{2} \mathrm{O}_{3} / 316$ & $6.66 \pm 1.2$ & $\mathrm{Al}_{2} \mathrm{O}_{3} / 304$ & $16.61 \pm 1.29$ \\
\hline
\end{tabular}

\section{Conclusions and Future Work}

Singly-coated steel substrates have been tested for resistance to corrosion and attenuation of neutrons and gammas. The two stainless steels (type 304 and 316) are clearly more corrosion resistant than the A36 carbon steel. Based on corrosion rates calculated from electrochemical means, the coated samples corrode at similar rates to bare samples. This is likely due to the corrosive solution reaching the substrate through pores in the coatings. This can possibly be alleviated by increasing coating thickness, adding additional layers, and/or adding a metallic buffer layer to improve adhesion and reduce porosity. Moreover, different coating mechanisms have been shown to increase film thickness and reduce porosity, namely suspension, 
sol-gel, and electrochemical plating, over plasma deposition [30]. However, in order for the deposition process to be applied on an industrial scale, the method of choice must be scalable, and the liquid-based coating mechanisms are not practical for the large HLW canisters for which these coatings are intended. This reduces the feasible options to physical vapor deposition (PVD), thermal sprays, or similar technology but increases the viability of using cathode arcs and magnetron sputterdeposition techniques.

Corrosion rate tends to increase exponentially with increasing temperature for all materials tested, following an Arrhenius-type equation. Passive breakdown voltage, and hence the initiation potential for pitting, also decreases exponentially with increasing temperature, demonstrating the impact of temperature on macroscopic and localized corrosion.

Corrosion among bare and coated stainless steel samples is comparable. The corrosion current and passive breakdown potential does not vary significantly between bare and coated materials, as the corrosion rates are all within one standard deviation for each sample of stainless steel. The very thin coatings function similarly to passive films that form on the bare steel. It remains to be seen if thicker, multilayer coatings are able to protect against pitting and other forms of localized corrosion that plague passive stainless steels.

The coated carbon steel samples show more inhibited corrosion than the bare steel. Coated samples of A36 steel have measured corrosion rates that are less than that of the bare steel by greater than one standard deviation. This may indicate that the coatings are able to reduce the rate of uniform corrosion experienced by carbon steels.

It should be noted that the coatings did not act to accelerate corrosion despite $\mathrm{Ti}$ and $\mathrm{Zr}$ being nobler than either stainless or carbon steel.

Future work includes implementing multilayered coatings, which will consist of single-material and composite layers. Deposition will continue with reactive magnetron sputtering. The goal will be to determine how the coating materials function together in reducing uniform and localized corrosion (pitting and intergranular), as well as their use as a barrier to hydrogen diffusion and mechanical wear.

It is envisioned that the multilayer coating systems are able to greatly increase resistance to pitting corrosion in stainless steel, specifically in the presence of chloride ions. Moreover, the multilayer coatings will be tested on carbon steel to determine if uniform corrosion may be reduced to manageable levels. In that case, the reduced susceptibility of carbon steel to pitting corrosion and SCC under normal circumstances may warrant further investigation for its use in high level waste storage containers. A metal that corrodes uniformly has a more predictable service life than a metal that is susceptible to failure based on stress corrosion cracking.
It should be noted that hydrogen embrittlement and cracking is of greater concern with ferritic steels, such as A36, than with austenitic steels. Hydrogen has low solubility, high mobility (diffusivity), and a high probability of being trapped at defect sites in iron (and hence carbon steel) [31], causing it to be prone to hydrogen cracking. The face centered cubic (FCC) structure of austenitic steels inhibits diffusion of hydrogen into the lattice, making them mostly immune to hydrogen cracking [7]. Resistance of the coating materials to hydrogen diffusion and embrittlement will be investigated in the next phase of this study.

\section{Acknowledgment}

Work supported by the US Department of Energy under contract DE-NE0000736 Project NEUP 13-5427.

The authors would also like to thank Caroline Campbell, Alexis Tuason, and Jordan Schweigert of Virginia Tech, and Sean Kerrigan and John Echols of the University of Florida for their contributions in sample preparation and nanoindentation, and their diligent aid in the completion of this work.

\section{References}

[1] M.-S. Yim, K.L. Murty, Materials issues in nuclear-waste management, Jom. 52 (2000) 26-29. doi:10.1007/s11837-000-0183-0.

[2] J.C. Farmer, G.E. Gdowski, R.D. McCright, H.S. Ahluwahlia, Corrosion models for performance assessment of high-level radioactive-waste containers, Nucl. Eng. Des. 129 (1991) 57-88. doi:10.1016/0029-5493(91)90329-G.

[3] J. a. Beavers, N.G. Thompson, R.N. Parkins, Stress-corrosion cracking of low strength carbon steels in candidate high level waste repository environments: Environmental effects, Nucl. Chem. Waste Manag. 5 (1985) 279-296. doi:10.1016/0191-815X(85)90004-X.

[4] W.C. Bare, L.D. Torgerson, Dry Cask Storage Characterization CASTOR V / 21 Cask Opening and Examination, 2001.

[5] J. Farmer, V. Pasupathi, P. Nair, G. Gordon, G. Gdowski, S. Carroll, et al., Technical Basis Document No. 6: Waste Package and Drip Shield Corrosion, 2003.

[6] J.D. Lambert, S. Bakhtiari, I. Bodnar, C. Kot, J. Pence, NRC Job Code V6060: Extended In-Situ and Real Time Monitoring Task 3: Long-Term Dry Cask Storage of Spent Nuclear Fuel, (2012) 1-55.

[7] R.W. Revie, H.H. Uhlig, Corrosion and Corrosion Control, 4th ed., John Wiley \& Sons, 2008.

[8] A. Kosaki, Evaluation method of corrosion lifetime of conventional stainless steel canister under oceanic air environment, Nucl. Eng. Des. 238 
(2008) 1233-1240.

doi:10.1016/j.nucengdes.2007.03.040.

[9] D.C. Kunerth, T. McJunkin, M. McKay, S.

Bakhtiari, Inspection of Used Fuel Dry Storage

Casks, (2012) 1-20.

[10] G.P. Marsh, K.J. Taylor, An assessment of carbon steel containers for radioactive waste disposal, Corros. Sci. 28 (1988) 289-320.

http://www.sciencedirect.com/science/article/pii/00 $10938 X 88901114$.

[11] R.A. Cottis, Stress Corrosion Cracking, Corrosion and Protection Centre, UMIST, 2000. http://www.npl.co.uk/upload/pdf/stress.pdf

[12] R. Checchetto, M. Bonelli, L. Gratton, a Miotello, a Sabbioni, L. Guzman, et al., Analysis of the hydrogen permeation properties of TiN-TiC bilayers deposited on martensitic stainless steel, Surf. Coatings Technol. 83 (1996) 40-44. doi:10.1016/0257-8972(96)02851-4.

[13] C.C. Scheffing, K. Jagannadham, M.S. Yim, M. Bourham, Properties of Titanium-Nitride for HighLevel Waste Packaging Enhancement, Rad. Waste Mgmt. Dispos. 156 (2006) 213-221.

[14] S.W. Dean, Electrochemical Techniques for Corrosion Engineering, in: Electrochem. Methods Corros. Test., National Association of Corrosion Engineers, Houston, TX, 1986.

[15] O. a. Petrii, R.R. Nazmutdinov, M.D. Bronshtein, G. a. Tsirlina, Life of the Tafel equation: Current understanding and prospects for the second century, Electrochim. Acta. 52 (2007) 3493-3504. doi:10.1016/j.electacta.2006.10.014.

[16] M. Stern, A.L. Geary, Electrochemical Polarization, J. Electrochem. Soc. 104 (1957) 559. doi:10.1149/1.2428653.

[17] M. Bouklah, B. Hammouti, M. Lagrenée, F. Bentiss, Thermodynamic properties of 2,5-bis(4methoxyphenyl)-1,3,4-oxadiazole as a corrosion inhibitor for mild steel in normal sulfuric acid medium, Corros. Sci. 48 (2006) 2831-2842. doi:10.1016/j.corsci.2005.08.019.

[18] M. a M. Ibrahim, S.S. Abd El Rehim, M.M. Hamza, Corrosion behavior of some austenitic stainless steels in chloride environments, Mater. Chem. Phys. 115 (2009) 80-85. doi:10.1016/j.matchemphys.2008.11.016.

[19] M.H. Wahdan, The synergistic inhibition effect and thermodynamic properties of 2-

mercaptobenzimidazol and some selected cations as a mixed inhibitor for pickling of mild steel in acid solution, Mater. Chem. Phys. 49 (1997) 135-140. doi:10.1016/S0254-0584(96)01925-6.

[20] a. Zarrouk, B. Hammouti, H. Zarrok, S.S. AlDeyab, M. Messali, Temperature effect, activation energies and thermodynamic adsorption studies of L-Cysteine Methyl Ester Hydrochloride as copper corrosion inhibitor in nitric acid 2M, Int. J. Electrochem. Sci. 6 (2011) 6261-6274.

[21] R.S. Oguike, Corrosion Studies on Stainless Steel ( FE6956 ) in Hydrochloric Acid Solution, Adv. Mater. Phys. Chem. 4 (2014) 153-163. doi:10.4236/ampc.2014.48018.

[22] E.A. Gulbransen, The Transition State Theory of the Formation of Thin Oxide Films on Metals, J. Electrochem. Soc. 83 (1943) 301-317. doi:10.1149/1.3071546.

[23] N. Pessall, C. Liu, Determination of critical pitting potentials of stainless steels in aqueous chloride environments, Electrochim. Acta. 16 (1971) 19872003. doi:10.1016/0013-4686(71)85152-6.

[24] B.E. Wilde, E. Williams, The use of current/voltage curves for the study of localized corrosion and passivity breakdown on stainless steels in chloride media, Electrochim. Acta. 16 (1971) 1971-1985. doi:10.1016/0013-4686(71)85151-4.

[25] C.Y. Chao, L.F. Lin, D.D. MacDonald, A Point Defect Model for Anodic Passive Films, J. Electrochem. Soc. 128 (1981) 1194. doi:10.1149/1.2127591.

[26] D.D. Macdonald, The Point Defect Model for the Passive State, J. Electrochem. Soc. 139 (1992) 3434. doi:10.1149/1.2069096.

[27] L. Williams, R.J. Taylor, iR Correction: Part I. A Computerised Interrupt Method, J. Electroanal. Chem. Interfacial Electrochem. 108 (1980) 293303. doi:http://dx.doi.org/10.1016/S00220728(80)80338-X.

[28] ASTM, Standard Test Method for Conducting Cyclic Potentiodynamic Polarization Measurements for Localized Corrosion Susceptibility of, Annu. B. ASTM Stand. 86 (2010) 1-5. doi:10.1520/G006186R09.2.

[29] M. Dahmani, a. Et-Touhami, S.S. Al-Deyab, B. Hammouti, a. Bouyanzer, Corrosion inhibition of c38 steel in $1 \mathrm{M} \mathrm{HCl}$ : A comparative study of black pepper extract and its isolated piperine, Int. J. Electrochem. Sci. 5 (2010) 1060-1069.

[30] V. Meille, Review on methods to deposit catalysts on structured surfaces, Appl. Catal. A Gen. 315 (2006) 1-17. doi:10.1016/j.apcata.2006.08.031.

[31] D.E. Jiang, E. a. Carter, Diffusion of interstitial hydrogen into and through bcc Fe from first principles, Phys. Rev. B - Condens. Matter Mater. Phys. 70 (2004) 1-9. doi:10.1103/PhysRevB.70.064102. 